\title{
A study on internet-based autonomous learning in college Ehglish
}

\author{
Zhaoxu Han ${ }^{1}$, Weixia Fan ${ }^{2}$ \\ Shijiazhuang University of Economics, Shijiazhuang, CHINA \\ Hebei University of Science and Technology, Shijiazhuang, CHINA \\ hanzhaoxu@tom.com,weixiafan@126.com
}

\begin{abstract}
This paper analyses the influences of Internet on college English autonomous learning. It not only points out many problems that exist in autonomous learning process but also puts forward many effective methods to deal with its problems for the purpose of improving both teachers' professionalism and students' learning effect.
\end{abstract}

Keywords: Internet, autonomous learning, college English

\section{Introduction}

Currently, both with the Internet-based teaching environment has been built and English teaching curriculum reform in every education stage (elementary school, high school, college, etc) has been furthered, all the college students are able to involve in English autonomous learning effectively so that the shortage of insufficient teaching time could be made up to the utmost extent. Meanwhile, as stipulated in College English Curriculum Requirements, one of the most important symbols of the success of teaching mode reform lies in the formation of learning individualization and the development of learning autonomy. Therefore, due to the development of information technology and teaching reform, Internet-based platform autonomous learning of college
English is certain to provide more options and flexibilities for college students in order to develop their capability of both English language skills and comprehensive practice skills.

\section{Influence of Internet on English autonomous learning}

When it comes to the objectives of English classroom teaching, to teach students' techniques of English autonomous learning, is one of the top, which could guarantee the quality and effect of English learning both actively and sufficiently after class. There are three points that matter to college students who want to succeed in English autonomous learning, first, how to control the learning objectives successfully, second, how to choose learning activities freely, third, how to build up learning confidence smoothly. Therefore, English autonomous learning is regarded as an ability of involving the students into the whole process of learning, changing the passive learning attitudes and approaches into active ones so that learning effect could be enhanced. Meanwhile, with the booming development of information technology, English teaching has been experiencing the revolutionary changes.

Under such huge dramatic changing background, college English autonomous learning achieved enormous development as well, which has been deeply affected 
and shaped by Internet at the same time in the following three aspects.

\subsection{Internet is an ocean of information}

As well all know, the process of learning English is actually believed as an acquiring and handling information process. Compared with traditional learning one, most majorities of readers who get information by reading books cannot be provided enough information plus the poor speed and efficiency. However, because of the rapid development of Internet technology, anyone who owns one computer and Internet access are able to gain information easy and enjoy various learning resources as well, which also provide all kinds of essential information to practice English autonomous learning.

\subsection{Internet plays the role as a mediator}

As a matter of fact, autonomous learning is not supposed to

be treated as self-learning, it requires the learners to be supported by both teachers, teaching syllabus and systematic theories when they are carrying out the process of autonomous learning, moreover, all the learners are demanded to communicate among themselves simultaneously. The application of Internet and development of Information Technology has greatly contributed to the requirement of information exchanging during the process of autonomous learning. All the teaching activities and participants are entitled to take advantage of Internet as a platform to communicate, which ranging from traditional email form to current popular form such as QQ or Twitter. Not only all the teachers could direct and supervise their students learning process, but also all the students are capable of accomplishing diverse activities that used to be confined by traditional classroom such as further discussion, resources share and peer's evaluation etc so that the effi- ciency of autonomous learning can be boosted.

\subsection{Internet plays the role as a magnet}

Actually, Internet is a magnet that attracts all the young learners. There is no doubt that stimulating students' enthusiasm of learning is one of the best ways to gain the best teaching effect. During the traditional autonomous leaning process, students mainly depend on themselves to continue their study especially after class, to be specific, they make use of their spare time to read books in order to get information then they collect useful information and memorize some of which are meaningful to them. The whole process can not avoid boredom colour that finally result in achieving poor teaching effect especially for those students who do not have a strong willpower of learning. Fortunately, Internet emerges in time to break the ice and thoroughly changes the way of English learning, which not only provides enormous information from every aspect of all subjects but also offers an information-exchanging platform for them. Therefore, teachers who help and encourage students at any time have joined the army of students to engage in learning process.

\section{Problems of English autonomous learning under Internet environment}

Admittedly, under Internet-based platform environment, to develop a good habit of learning is a key factor for English autonomous learning. However, as the enrolment expansion of colleges in recent years, students' numbers of one class has dramatically increased. To cultivate student's autonomous learning ability has become the top issue of college English teaching. Nevertheless, certain accomplishment has been made in current scientific research and teaching reform, which still can not cope with all sorts of prob- 
lems in teachers, students and learning resources etc.

\subsection{Problems in teacher themselves}

With regard to the popular Internet-based autonomous learning, all college teachers can be divided into three groups. Group one teachers they usually hold the belief that Internet is omnipotent, which totally depend on support even guide of Internet techniques, students do not need teachers any more to study and can still learn well. In terms of this way, teachers in this group take it for granted that English aptitude could be guaranteed and achieved by assigning a great number of homework and exercises. Contrary to group one teacher, the second group adopts a hostile attitude towards autonomous learning under Internet environment, they consider that the more information the Internet could offer the more attention will be wasted in their study, such as many irrelative information can distract them or huge lures of entertainment could happen. Therefore, group two teachers they prefer to depreciate the function of Internet and then take measures of instilling into hard information by making use of limited classroom teaching time, which inevitably lead to hurt of students' learning initiative. Group three teachers show a sense of fear that is natural to have but still can be overcame in the future. These teachers who definitely are experienced classroom teachers do not dare to make an attempt to employ new teaching tools and worry about their own competence of using modern teaching means. Because their passive attitude and fear for Internet, students lose their passion for Internet-based autonomous learning in English.

\subsection{Problems in student themselves}

There are two main perspectives when talking about students' problems in autonomous learning process. On the one hand, it is common that students have a poor capability of autonomous learning due to Chinese teaching system for years. Chinese cramming method of teaching mode results in students' lack of necessary independent learning ability and critical thinking ability, once they lose their teachers' guidance they will definitely not know what to do. On the other hand, enthusiasm for autonomous learning is obviously insufficient because their free space are greatly limited by autonomous learning process. For example, college English teachers still get used to interfere in students' learning activities outside classroom with a great number of homework or assignments, which will inevitably hurt interest and passion of students who think the autonomous learning equals classroom teaching activity

\subsection{Problems in learning resources}

Recently, much more investment has been poured into English education by government such as a lot of autonomous learning software has been researched and developed. However, for the lack of united national standards for software, many teachers and students realize that not all the software are able to satisfy real need of autonomous learning activities such as some software's copy behaviour from the textbook. Moreover, a repeated learning of classroom teaching content is not only a waste of students' study time, but also a barrier to realize effective teaching. In a word, creative software and techniques are called for as well as exclusive autonomous learning centre should be built up and popularised.

\section{Methods of improving English autonomous learning under Inter- net environment}

In order to cope with all problems of Internet-based autonomous learning, all college English teachers are supposed to cor- 
rect their attitude and change their concepts.

Firstly, to believe in teachers, roles as guide, supervisor and co-worker will help to facilitate the process of autonomous learning. Teachers should guide them to understand English learning process is a long and complicated one; limited classroom teaching could not help them with successful English learning. Also, students are required to willingly develop English learning through their active participations into autonomous learning. As a supervisor teachers are demanded to not only concern about students' learning behaviour but also supervise their learning activities through Internet both in class and after class. As a co-worker, teachers are supposed to put into more energy and time to participate and facilitate their activities such as answering their problems, evaluating their performance or organizing certain activities for the purpose of improving students' learning ability and perfecting their learning approaches as well.

Secondly, to develop a correct attitude towards Internet-based autonomous learning is another key factor could enhance the effect. On the one hand, teachers are bond to improve their teaching techniques and professional knowledge, especially capability of mastering Internet and its technology. On the other hand, students should change their learning attitude towards autonomous learning in English. Students are real learning principal part of learning process and Internet is just a method, which has been offering good environment and condition to serve them plus their own subjective efforts.

Besides, national standards on Internetbased autonomous learning should be set up as early as possible so that the quality could be guaranteed; Internet-based autonomous learning centres in college should be established as many as possible as well in order to popularise modern learning mode and optimise learning environment; regular training course should also be offered to increase teachers' professionalism systematically.

\section{Conclusion}

Internet-based autonomous learning in English plays the key role in Chinese college English teaching reform. Currently, Chinese English teaching reform has been experiencing a dramatic change from teacher-centred mode to student-centred mode. Developing students' autonomous learning ability in English is bond to accelerate this huge changing process so that Chinese college English teaching quality will be extremely advanced.

\section{References}

[1] Jeremy Harmer. The Practice of English Language Teaching (Fourth Edition) .London: Pearson Education Limited, pp.394-400, 2007.

[2] Lynne T. Diaz-Rico. Strategies for teaching English Learners (Second Edition ) [M]. Boston: Pearson Education, Inc, pp.105-108, 2008. 